MATEC Web of Conferences 53, 01020 (2016)

DOI: $10.1051 /$ matecconf/20165301020

(C) Owned by the authors, published by EDP Sciences, 2016

\title{
Measuring the thermal resistance of typical multi-layer building walls using the accelerated measurement method
}

\author{
Daniil Zubkov ${ }^{1}$, Alexander Chusov ${ }^{2}$ and Dmitry Molodtsov²,a \\ ${ }^{1}$ Saint Petersburg National Research University of Information Technologies, Mechanics and Optics, Kronverksky \\ pr. 49, St. Petersburg 197101, Russia \\ ${ }^{2}$ Peter the Great St.Petersburg Polytechnic University, Polytechnicheskaya str. 29, St. Petersburg 195251, Russia
}

\begin{abstract}
This paper considers the application of accelerated thermal resistance measurement to typical constructions of multi-layer walls of buildings with thermal insulation. It is shown that it is possible to reduce the measurement time considering the results of preliminary modelling. The required calculations for some typical constructions of building walls were made. The examples of simulation results shown in this paper allow to reduce the thermal resistance measurement time by $15-20 \%$. There can be made calculations for other structures of building walls, following the presented method.
\end{abstract}

\section{Introduction}

The lack of thermal resistance of the main building structures is one of the main reasons for low energy efficiency of buildings built in the USSR in 1960-1990 years [1-4]. According to the research, in a traditional apartment house up to $40 \%$ of heat is lost through walls, $18 \%$ through windows, $10 \%$ through basement, 18\% through roof and 14\% through ventilation [5-8]. Heat loss is especially noticeable in the northern regions [9-11]. Usually buildings built before 1995 in central Russia have values of thermal resistance 2-3.5 times smaller than it should be according to the modern standards [12]. In 1995 in Russia the nation-wide regulatory requirements for thermal protection of buildings were established, increasing the resistance requirements for enclosing structures. Now it is regulated by SNiP 23-02-2003 "Thermal protection of buildings". Additional insulation on facades of buildings pays off in about 3.5 years [13-15], but it requires estimating of thermal resistance of the existing walls.

Methods for determination of thermal resistance, approved in Russia, require long-term measurements. For building walls, it takes more than 15 days, according to GOST [16]. Reduction of the measurement time will significantly simplify such work, reduce its cost and will make it easier to increase the energy efficiency of the buildings [17-19].

\footnotetext{
${ }^{a}$ Corresponding author: kovu@bigcats.ru
} 


\section{Materials and methods}

One method of measuring the thermal resistance of the wall is the thermal stabilization of its sides at different temperatures and measuring the heat flux through the wall. A noticeable drawback of it is that you must wait for the system to steady state, which can take up to 15 days.

A method of accelerated measurement of thermal resistance of homogeneous walls is considered in the patent [20]. It is shown that when considering homogeneous walls, the use of the half-sum of incoming and outgoing heat flows becomes constant much earlier than the whole system. That allows to take measurements significantly earlier than the system achieves a steady state. The essence of this method is clearly demonstrated in Figure 1.

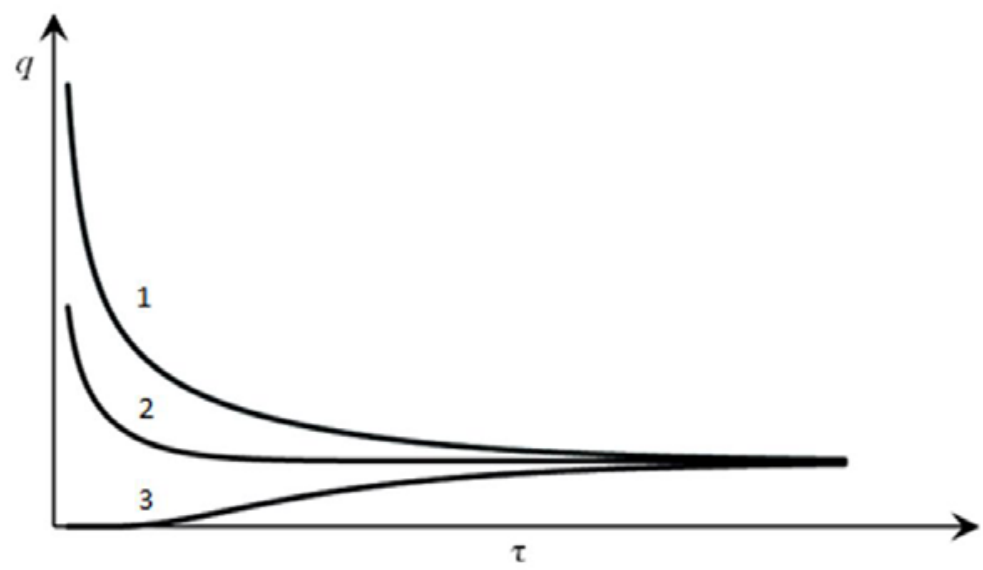

Figure 1. The essence of the original method. Time dependence of the incoming (1), outgoing (3) heat flows and their half-sum (2).

To determine the minimum measurement time with an error of less than $5 \%$ is used the following relationship:

where

$$
a \tau / h^{2}>0.1
$$

$a$ - thermal diffusivity of the wall;

$h$ - its thickness;

$\tau-$ the measurement time.

As shown in [21], the use of this method for measuring the thermal resistance of multi-layer walls made of materials with significantly different thermal properties allows to reduce the measurement time by about $15 \%$, but it is hard to estimate the minimum measurement time in advance with sufficient precision.

Since the structural elements the walls of buildings are built of (bricks, concrete blocks, sheets of insulation, etc.) have a number of standard dimensions, it is possible to produce a computer simulation of the measurement of thermal resistance for a number of typical constructions of walls [22]. Taking into account the results of the simulation, it is possible to make accelerated measurement of deviations of the expected thermal resistance values, taking the measurement time with some excess to take into account the possible influence of changed material properties.

\section{Results and discussion}

As was shown in [21], for the walls of brick and concrete without thermal insulation layers the relationship (1) works completely. In this paper are considered some models of building walls 
consisting of brick, concrete, polystyrene and mineral wool in the form of blocks in various combinations.

Let us consider in detail the case of a brick wall with a layer of polystyrene foam insulation and gypsum layers on both sides. The simulation was performed in the program Heat 2. A twodimensional model represents a part of a vertical wall with the temperature of $t=20{ }^{\circ} \mathrm{C}$ at the inner surface and $\mathrm{t}=0{ }^{\circ} \mathrm{C}$ on an outer surface. Adiabatic conditions are applied to the horizontal surfaces [21]. The material properties are taken from the built-in library of the program. Figure 2 shows the structure of the model, Figure 3 - the temperature field in a steady state, and Figure 4 - the specific heat flux field.
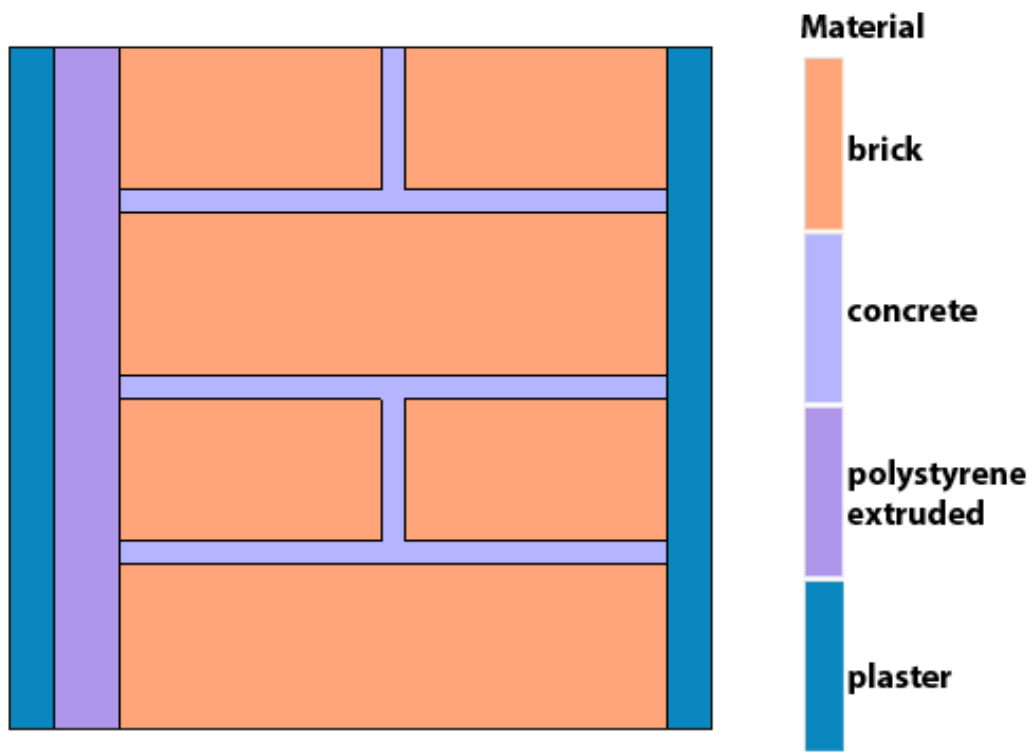

Figure 2. Structure of the model, brick wall with a layer of thermal insulation and two layers of plaster.
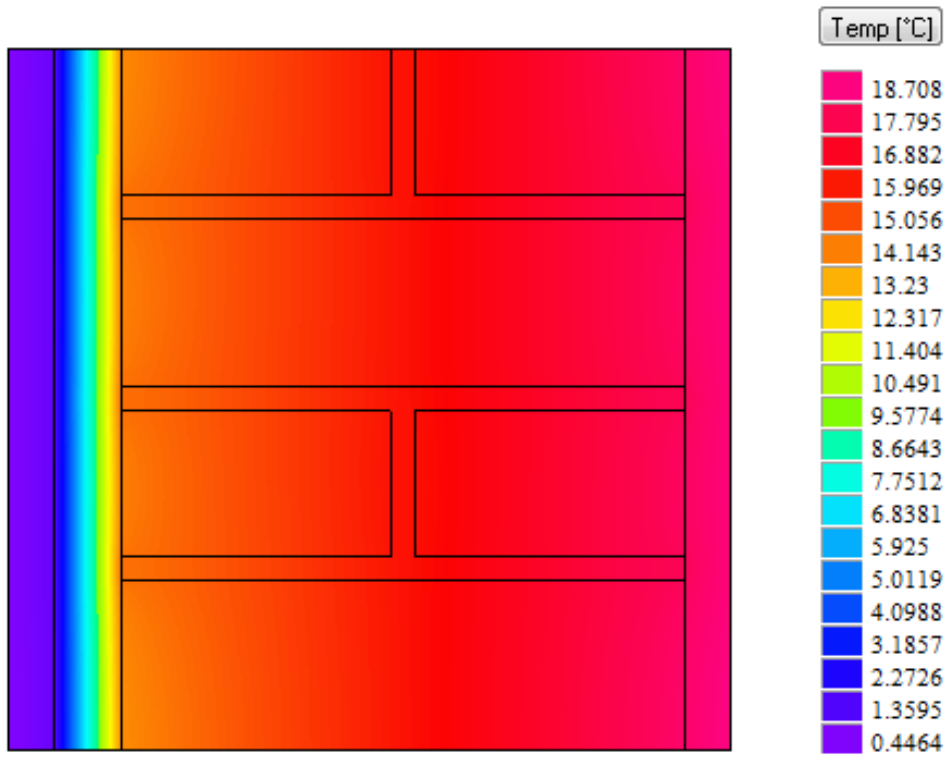

Figure 3. Results of the simulation. Temperature field in a steady state. 

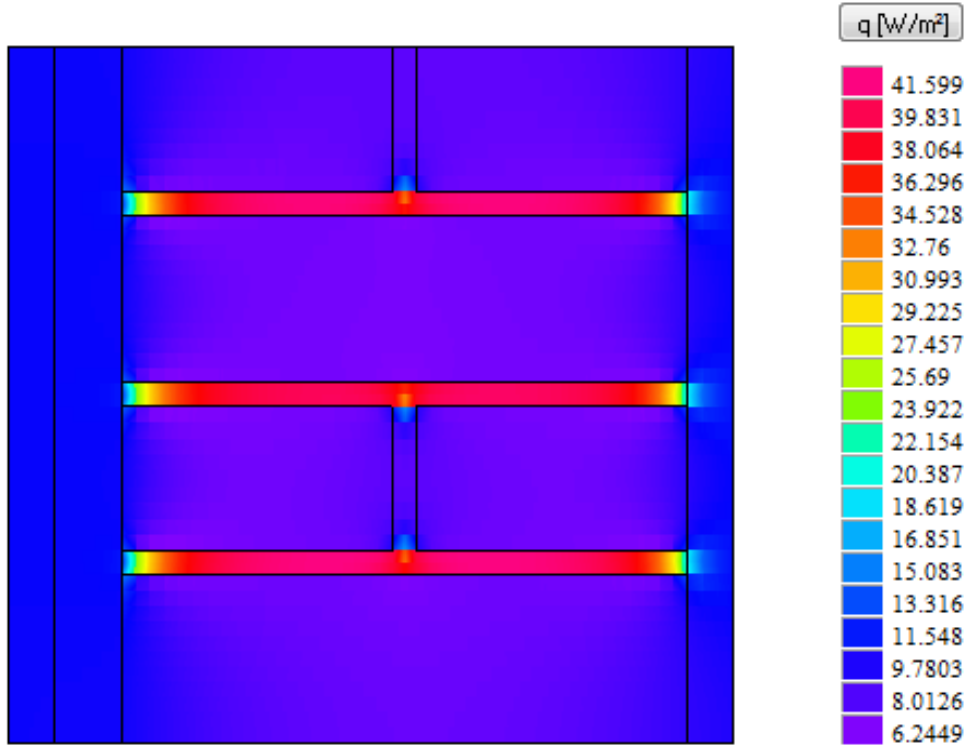

Figure 4. Results of the simulation. Specific heat flux field in a steady state.

During the simulation the program tracked heat flux on both of the vertical surfaces within 15 days of virtual time in increments of 15 minutes. The results are presented in Figure 5.

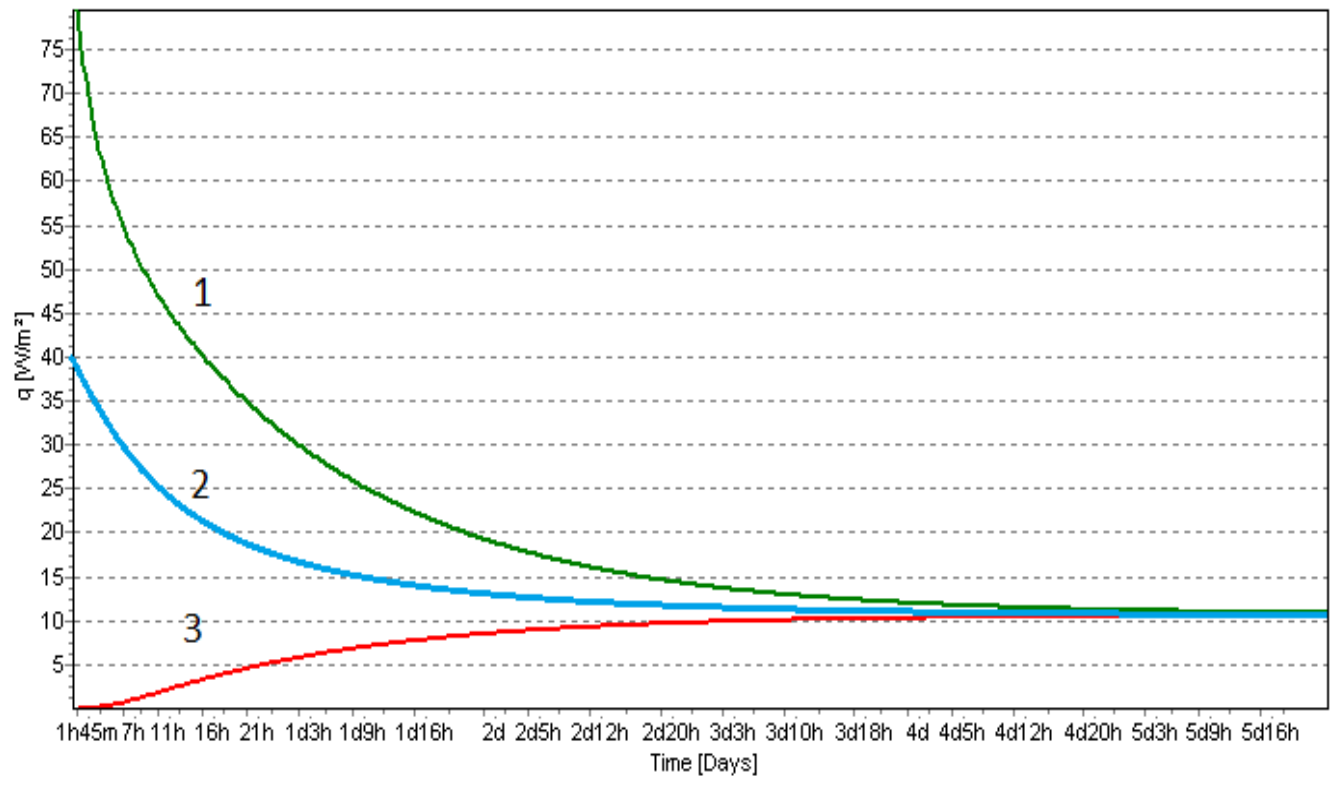

Figure 5. Results of the simulation. Time dependence of the incoming (1), outgoing (3) heat flows and their halfsum (2).

It was found that with a deviation of 5\% the values of incoming and outgoing heat flows become equal to the flows obtained after 15 days in 5 days and 2 hours $\left(\tau_{1}\right)$, and half the sum of these flows becomes equal to the same flows in 3 days and 20 hours $\left(\tau_{2}\right)$. Thus, the reducing of measurement time is $\Delta=24,6 \%$. Similarly, were considered some other types of building wall structures. The results are shown in Table 1. 
Table 1. Simulation results for various wall designs.

\begin{tabular}{|c|c|c|c|}
\hline Wall structure & $\tau_{1}, \mathrm{~h}$ & $\tau_{2}, h$ & $\Delta, \%$ \\
\hline $\begin{array}{c}\text { One brick }(250 \mathrm{~mm}) \text {, polystyrene foam }(20 \mathrm{~mm}), \\
\text { plaster }(2 \times 20 \mathrm{~mm})\end{array}$ & 77 & 62 & 19.5 \\
\hline $\begin{array}{c}\text { One brick }(250 \mathrm{~mm}) \text {, polystyrene foam }(30 \mathrm{~mm}), \\
\text { plaster }(2 \times 20 \mathrm{~mm})\end{array}$ & 122 & 92 & 24.6 \\
\hline $\begin{array}{c}\text { One brick }(250 \mathrm{~mm}) \text {, polystyrene foam }(50 \mathrm{~mm}), \\
\text { plaster }(2 \times 20 \mathrm{~mm})\end{array}$ & 142,5 & 117 & 17.9 \\
\hline $\begin{array}{c}\text { One brick }(250 \mathrm{~mm}) \text {, polystyrene foam }(20 \mathrm{~mm}) \text {, } \\
\text { plaster }(2 \times 20 \mathrm{~mm})\end{array}$ & 172,5 & 140 & 18.8 \\
\hline $\begin{array}{c}\text { One brick }(250 \mathrm{~mm}), \text { mineral wool }(50 \mathrm{~mm}), \\
\text { plaster }(2 \times 20 \mathrm{~mm})\end{array}$ & 93,5 & 80 & 14.4 \\
\hline $\begin{array}{c}\text { One brick }(250 \mathrm{~mm}), \text { mineral wool }(100 \mathrm{~mm}), \\
\text { plaster }(2 \times 20 \mathrm{~mm})\end{array}$ & 128 & 112 & 12.5 \\
\hline
\end{tabular}

Thus, the use of the presented simulation results allows to reduce the thermal resistance measurement time by $15-20 \%$ ( $18 \%$ on the average for the provided examples). The results for other combinations obtained by a similar method also can be used to simplify the renovation of old buildings to increase their energy efficiency.

\section{Conclusions}

1. The results obtained by the presented method can be used to simplify the process of renovation of old buildings.

2. For acceleration the measuring of thermal resistance of typical design multilayer insulated wall can be used the results of calculations presented in this paper, or obtained by the same method.

3. The use of the calculations presented in this paper allows to reduce measurement time by $15-20 \%$.

\section{References}

1. D. Nemova, V. Murgul, V. Pukhkal, A. Golik, E. Chizhov, N. Vatin, Journal of Applied Engineering Science, 12(1), 37-44 (2014)

2. A. Borodinecs, B. Gaujena, 10th International Conference on Healthy Buildings 2012, 2, 1715 $1722(2012)$

3. O. Smorygo, V. Mikutski, A. Marukovich, V. Sadykov, V. Usoltsev, N. Mezentseva, A. Borodinecs, O. Bobrenok, IOP Conference Series: Materials Science and Engineering, 23 (2011)

4. V. Murgul, Journal of Applied Engineering Science, 12 (1), 1-10 (2014)

5. A. Borodinecs, J. Zemitis, A. Kreslins, B. Gaujena, 10th International Conference on Healthy Buildings 2012, 2, 1114-1119 (2012)

6. A. Borodinecs, B. Gaujena, J. Zemitis, A. Kreslins, 12th International Conference on Indoor Air Quality and Climate 2011, 2, 973-978 (2011)

7. A. Borodinecs, Z. Budjko, 9th International Conference and Exhibition - Healthy Buildings 2009 (2009)

8. A. Borodiñecs, A. Kreslinšs, E. Dzelzitis, A. Krumiņš, IAQVEC 2007 Proceedings - 6th International Conference on Indoor Air Quality, Ventilation and Energy Conservation in Buildings: Sustainable Built Environment, 1, 361-368 (2007)

9. A. Borodinecs, J. Zemitis, A. Prozuments, World Renewable Energy Forum, WREF 2012, Including World Renewable Energy Congress XII and Colorado Renewable Energy Society (CRES) Annual Conferen, 6, 4181-4186 (2012) 
10. A. Borodinecs, A. Kreslins, Proceedings - 28th International PLEA Conference on Sustainable Architecture + Urban Design: Opportunities, Limits and Needs - Towards an Environmentally Responsible Architecture, PLEA 2012 (2012)

11. V.V Okrepilov, V.N. Krutikov, G.I. El'kin, Measurement Techniques, 57 (2),109-116 (2014)

12. A. Borodinecs, A. Kreslins, Proceedings of Conference: Air Conditioning and the Low Carbon Cooling Challenge - Windsor 2008 Conference (2008)

13. D.V. Nemova, N.I. Vatin, A.S. Gorshkov, A.V. Kashabin, P.P. Rymkevich, D.N. Tseitin, Construction of Unique Buildings and Structures, 8(23), 93-115 (2014)

14. E. Aronova, Ž. Radovanović, V. Murgul, N. Vatin, M. Shvarts, Applied Mechanics and Materials, 725-726, 1505-1511 (2015)

15. V.L. Kvint, V.V Okrepilov, Herald of the Russian Academy of Sciences, 84 (3), 188-200 (2014)

16. GOST [Russian government technical requirements] 26254-84. Buildings and structures. Methods for determination of thermal resistance of enclosing structures.

17. N. Vatin, M. Petrichenko, D. Nemova, A. Staritcyna, D. Tarasova, Applied Mechanics and Materials, 633-634, 1023-1028 (2014)

18. N.I. Vatin, D.V. Nemova, D.S. Tarasova, A.A. Staritcyna, Advanced materials research, 953-954, 854-870 (2014)

19. V.V Okrepilov, A.Yu. Smirnov, Measurement Techniques, 56(1), 54-60 (2013)

20. V.A. Korablev, A.S. Nekrasov, D.S. Nechaev, inventors and assignee. Measurement of heat conductivity and heat resistance of construction Structure. Russian Federation patent 2527128 RU (August 08, 2014)

21. D.V. Zubkov, K.S. Tikhomirov, V.A Korablev, Proseedings of best papers of XLIII Week of Science in St.-Petersburg Polytechnic University, 306-312 (2014)

22. D. Zubkov, A. Chusov, D. Molodtsov, Proceedings SPbUCEMF 2015, Urban Civil Engineering and Municipal Facilities, Saint-Petersburg, Russia; 18-20 March 2015. CD-ROM (2015) 